Article

\title{
Genetic Characterization of Methicillin-Resistant Staphylococcus aureus Isolates from Human Bloodstream Infections: Detection of MLS $_{\mathrm{B}}$ Resistance
}

Vanessa Silva ${ }^{1,2,3,4}{ }^{\complement}$, Sara Hermenegildo ${ }^{1,2,3,4}$, Catarina Ferreira ${ }^{5}$, Célia M. Manaia ${ }^{5}{ }^{\circ}$, Rosa Capita ${ }^{6,7}\left(\mathbb{D}\right.$, Carlos Alonso-Calleja ${ }^{6,7} \mathbb{D}^{\text {, Isabel Carvalho }}{ }^{1,2,3,4}$, José Eduardo Pereira ${ }^{8}$, Luis Maltez $^{8}\left(\mathbb{D}\right.$, José L. Capelo ${ }^{9,10}$, Gilberto Igrejas ${ }^{2,3,4}$ and Patrícia Poeta ${ }^{1,4, *(D)}$

1 Microbiology and Antibiotic Resistance Team (MicroART), Department of Veterinary Sciences, University of Trás-os-Montes and Alto Douro (UTAD), 5001-801 Vila Real, Portugal; vanessasilva@utad.pt (V.S.); sara-1603@hotmail.com (S.H.); isabelcarvalho93@hotmail.com (I.C.)

2 Department of Genetics and Biotechnology, University of Trás-os-Montes and Alto Douro (UTAD), 5001-801 Vila Real, Portugal; gigrejas@utad.pt

3 Functional Genomics and Proteomics Unit, University of Trás-os-Montes and Alto Douro (UTAD), 5001-801 Vila Real, Portugal

4 Associate Laboratory for Green Chemistry-LAQV, Chemistry Department, Faculty of Science and Technology, University Nova of Lisbon, 2829-516 Lisbon, Portugal

5 CBQF-Centro de Biotecnologia e Química Fina-Laboratório Associado, Universidade Católica Portuguesa, Escola Superior de Biotecnologia, 4169-005 Porto, Portugal; aferreira@porto.ucp.pt (C.F.); cmanaia@porto.ucp.pt (C.M.M.)

6 Department of Food Hygiene and Technology, Veterinary Faculty, University of León, 24071 León, Spain; rosa.capita@unileon.es (R.C.); carlos.alonso.calleja@unileon.es (C.A.-C.)

7 Institute of Food Science and Technology, University of León, 24071 León, Spain

8 Veterinary and Animal Science Research Center (CECAV), University of Trás-os-Montes and Alto Douro (UTAD), 5001-801 Vila Real, Portugal; jeduardo@utad.pt (J.E.P.); lmaltez@utad.pt (L.M.)

9 BIOSCOPE Group, LAQV@REQUIMTE, Chemistry Department, Faculty of Science and Technology, NOVA University of Lisbon, 1349-008 Almada, Portugal; jlcm@fct.unl.pt

10 Proteomass Scientific Society, 2825-466 Costa de Caparica, Portugal

* Correspondence: ppoeta@utad.pt; Tel.: +35-125-935-04-66; Fax: +35-125-935-06-29

Received: 15 June 2020; Accepted: 30 June 2020; Published: 3 July 2020

\begin{abstract}
In this study we aimed to characterize antimicrobial resistance in methicillin-resistant Staphylococcus aureus (MRSA) isolated from bloodstream infections as well as the associated genetic lineages of the isolates. Sixteen MRSA isolates were recovered from bacteremia samples from inpatients between 2016 and 2019. The antimicrobial susceptibility of these isolates was tested by the Kirby-Bauer disk diffusion method against 14 antimicrobial agents. To determine the macrolide-lincosamide-streptogramin B $\left(\mathrm{MLS}_{\mathrm{B}}\right)$ resistance phenotype of the isolates, erythromycin-resistant isolates were assessed by double-disk diffusion (D-test). The resistance and virulence genes were screened by polymerase chain reaction (PCR). All isolates were characterized by multilocus sequence typing (MLST), spa typing, staphylococcal chromosomal cassette mec (SCCmec) typing, and accessory gene regulator (agr) typing. Isolates showed resistance to cefoxitin, penicillin, ciprofloxacin, erythromycin, fusidic acid, clindamycin, and aminoglycosides, confirmed by the presence of the blaZ, $\operatorname{ermA}$, $\operatorname{erm} \mathrm{C}, m p h \mathrm{C}, m s r \mathrm{~A} / \mathrm{B}, \operatorname{aac}\left(6^{\prime}\right)$-Ie-aph(2")-Ia, and $\operatorname{ant}\left(4^{\prime}\right)$-Ia genes. Three isolates were Panton-Valentine-leukocidin-positive. Most strains $(n=12)$ presented an inducible MLS $_{\mathrm{B}}$ phenotype. The isolates were ascribed to eight spa-types ( $\mathrm{t} 747, \mathrm{t} 002, \mathrm{t} 020, \mathrm{t} 1084, \mathrm{t} 008, \mathrm{t} 10682, \mathrm{t} 18526$, and t1370) and four MLSTs (ST22, ST5, ST105, and ST8). Overall, most $(n=12)$ MRSA isolates had a multidrug-resistance profile with inducible $M_{L} S_{B}$ phenotypes and belonged to epidemic MRSA clones.
\end{abstract}


Keywords: MRSA; EMRSA-15; $\mathrm{MLS}_{\mathrm{B}}$; bacteremia; bloodstream infections

\section{Introduction}

Staphylococcus aureus is an opportunist human pathogen responsible for numerous types of infections, from skin infections, such as abscesses or infected wounds, to life-threatening conditions, such as endocarditis, osteomyelitis, or septicemia [1]. Some S. aureus strains can be quite virulent due to the combined action of several virulence factors, the most important being Panton-Valentine leukocidin (PVL) and toxic shock syndrome toxin, associated with immune evasion, tissue adhesion, and host cell injury [2]. S. aureus is known for its ability to acquire antibiotic resistance determinants. In fact, $S$. aureus has become an important cause of nosocomial infections, particularly methicillin-resistant S. aureus (MRSA), which is usually associated with a multidrug-resistance profile [3]. Consequently, MRSA infections are difficult to treat and are a leading cause of morbidity and mortality, especially among hospitalized patients and humans with weakened immune systems [4]. Due to the increase of MRSA strains, macrolides, lincosamides, and streptogramin $\mathrm{B}\left(\mathrm{MLS}_{\mathrm{B}}\right)$ were often used to treat MRSA infections, which led to a subsequent cross-resistance to these antibiotics [5]. Different mechanisms are responsible for the $\mathrm{MLS}_{\mathrm{B}}$ resistance, the most common being the target modification mediated by the erm (erythromycin ribosome methylase) gene [6]. In staphylococci, erm $\mathrm{A}$ and erm $\mathrm{C}$ are the main genes conferring the $\mathrm{MLS}_{\mathrm{B}}$ resistance phenotype, which can be constitutive or inducible [7]. Healthcare-associated MRSA rates vary considerably across countries in Europe, with a high prevalence in Southwest Europe and a lower prevalence in Northeast Europe [8]. The prevalence of MRSA in Portugal has remained one of the highest among the European countries in recent years-around $40 \%$ of S. aureus isolates from hospitalized individuals with infection in Portugal have been identified as MRSA. The predominant clonal complexes responsible for hospital infections in Portugal are CC22 and CC5, with the epidemic methicillin-resistant Staphylococcus aureus 15 (EMRSA-15) clone being the most prevalent [9].

S. aureus is considered one of the most important and common pathogens causing bloodstream infections and is the second leading cause of sepsis in industrialized countries [10]. Both hospitaland community-acquired MRSA bacteremia are associated with various clinical manifestations, such as metastatic infections, endocarditis, septic arthritis, osteomyelitis, and septic shock [11]. Community-acquired MRSA bacteremia has now surpassed hospital-acquired bacteremia worldwide, and it is frequently associated with other diseases, such as diabetes, ulcers, or chronic renal disease [12]. Despite the existence of an adequate treatment, MRSA is responsible for mortality rates of $20 \%$ to $40 \%$ in a period of 30 days [13]. Given the extreme severity of clinical complications from a generalized infection caused by $S$. aureus and its association with resistance to methicillin and most $\beta$-lactam antibiotics, it is extremely important to study the genetic characteristics of the most prevalent strains responsible for bacteremia in order to more effectively target the strategies for controlling these infections [14]. This study aimed to isolate and characterize the antimicrobial resistance and genetic lineages of MRSA strains isolated from bloodstream infections.

\section{Results}

A total of 16 MRSA isolates were obtained from 103 hospitalized patients with bacteremia over the 3-year study period, corresponding to a patient incidence of $15.5 \%$. Table 1 shows the genotypical characterization of the MRSA strains. All isolates were resistant to cefoxitin and harbored the mecA gene. Eleven isolates belonged to SCCmec type IV and five to type II. The isolates were ascribed to eight spa types ( $\mathrm{t} 747, \mathrm{t} 002, \mathrm{t} 020, \mathrm{t} 1084, \mathrm{t} 008, \mathrm{t} 10682, \mathrm{t} 18526$, and $\mathrm{t} 1370)$. The 16 isolates were grouped into five different sequence types (STs), namely ST22 $(n=9), \operatorname{ST} 5(n=2), \operatorname{ST} 105(n=2), \operatorname{ST} 8(n=2)$, and ST5984 $(n=1)$. ST5984 was first described in this study and differs from ST105 by a one-point mutation on the arcC locus. The isolate categorized as ST5984 belonged to spa-type t1084, SCCmec, and $a g r$ type II and presented resistance to penicillin, erythromycin, ciprofloxacin, and fusidic acid. 
Table 1. Antimicrobial resistance, virulence factors, and molecular characteristics of methicillin-resistant Staphylococcus aureus (MRSA) strains isolated from blood cultures.

\begin{tabular}{|c|c|c|c|c|c|c|c|}
\hline \multirow{2}{*}{ Isolate } & \multicolumn{2}{|c|}{ Antimicrobial Resistance } & \multirow{2}{*}{ Virulence } & \multicolumn{3}{|c|}{ Molecular Typing } & \multirow[b]{2}{*}{$a g r$} \\
\hline & Phenotype & Genotype $^{a}$ & & MLST (CC) & spa & sCCmec & \\
\hline VS2761 & FOX, PEN, ERY, DA ${ }^{1}$, CIP & $m e c \mathrm{~A}, \operatorname{erm} \mathrm{C}, m s r(\mathrm{~A} / \mathrm{B})$ & $h l \mathrm{~A}$ & $22(22)$ & $\mathrm{t} 747$ & IV & I \\
\hline VS2762 & FOX, PEN, ERY, DA ${ }^{2}, \mathrm{CN}, \mathrm{CIP}$ & $\begin{array}{c}m e c \mathrm{~A}, \operatorname{blaZ}, \operatorname{erm} \mathrm{A}, \operatorname{msr}(\mathrm{A} / \mathrm{B}), \\
\operatorname{acc}\left(6^{\prime}\right)-\mathrm{Ie}-\operatorname{aph}\left(2^{\prime \prime}\right)-\mathrm{Ia}\end{array}$ & $h l \mathrm{~A}$ & $105(5)$ & t002 & II & II \\
\hline VS2763 & FOX, PEN, CIP & mecA, blaZ & $h l A, h l \mathrm{~B}$, et $A$ & $22(22)$ & $\mathrm{t} 747$ & IV & I \\
\hline VS2764 & FOX, PEN, ERY, DA ${ }^{2}, \mathrm{CIP}$ & $m e c \mathrm{~A}, b l a \mathrm{Z}, \operatorname{erm} \mathrm{C}, m s r(\mathrm{~A} / \mathrm{B}), m p h \mathrm{C}$ & $h l \mathrm{~A}$, et $A$ & $22(22)$ & t747 & IV & I \\
\hline VS2765 & FOX, PEN, ERY, DA ${ }^{2}, \mathrm{CIP}$ & $m e c \mathrm{~A}$, blaZ, $\operatorname{erm} \mathrm{C}, m s r(\mathrm{~A} / \mathrm{B}), m p h \mathrm{C}$ & $l u k F / l u k S-\mathrm{PV}, h l \mathrm{~A}, h l \mathrm{~B}$, et $\mathrm{A}$ & $22(22)$ & $\mathrm{t} 747$ & IV & I \\
\hline VS2766 & FOX, PEN, ERY, DA ${ }^{1}, \mathrm{CN}, \mathrm{TOB}, \mathrm{CIP}$ & $\begin{array}{c}\text { mec } \mathrm{A}, \text { blaZ, } \operatorname{erm} \mathrm{C}, m s r(\mathrm{~A} / \mathrm{B}), m p h \mathrm{C}, \\
\text { aac }\left(6^{\prime}\right)-\mathrm{Ie}-\operatorname{aph}\left(2^{\prime \prime}\right)-\mathrm{Ia}, \operatorname{ant}\left(4^{\prime}\right)-\mathrm{Ia}\end{array}$ & $l u k F / l u k S-\mathrm{PV}, h l \mathrm{~A}, h l \mathrm{~B}$, et $A$ & $22(22)$ & $\mathrm{t} 020$ & IV & I \\
\hline VS2767 & FOX, PEN, CIP & mecA, blaZ & $h l \mathrm{~A}, h l \mathrm{~B}$, et $A$ & $22(22)$ & $\mathrm{t} 747$ & IV & I \\
\hline VS2768 & FOX, PEN, ERY, DA ${ }^{2}, \mathrm{CIP}$ & $m e c \mathrm{~A}$, blaZ, erm $\mathrm{C}, m s r(\mathrm{~A} / \mathrm{B}), m p h \mathrm{C}$ & lukF/lukS-PV, hlA, et $A$ & $22(22)$ & $\mathrm{t} 747$ & IV & I \\
\hline VS2769 & FOX, PEN, ERY, DA 2 , CIP & $m e c \mathrm{~A}, b l a \mathrm{Z}, m s r(\mathrm{~A} / \mathrm{B}), m p h \mathrm{C}$ & $h l \mathrm{~A}, h l \mathrm{~B}$ & $5(5)$ & $\mathrm{t} 002$ & II & II \\
\hline VS2770 & FOX, PEN, ERY, DA ${ }^{2}$, CIP, FD & $m e c \mathrm{~A}$, blaZ, erm $\mathrm{A}, \operatorname{erm} \mathrm{C}, m s r(\mathrm{~A} / \mathrm{B}), m p h \mathrm{C}$ & $h l \mathrm{~A}, h l \mathrm{~B}$ & 5984 & $\mathrm{t} 1084$ & II & II \\
\hline VS2771 & FOX, PEN, ERY, DA ${ }^{2}, \mathrm{CIP}$ & $m e c \mathrm{~A}, \operatorname{bla\mathrm {Z}}, \operatorname{erm} \mathrm{C}, m s r(\mathrm{~A} / \mathrm{B}), m p h \mathrm{C}$ & $h l \mathrm{~A}$ & $8(8)$ & t008 & IV & I \\
\hline VS2772 & FOX, PEN, CIP & mecA, blaZ & $h l \mathrm{~B}$ & $5(5)$ & t002 & II & II \\
\hline VS2773 & FOX, PEN, ERY, DA ${ }^{2}, \mathrm{CIP}$ & $m e c \mathrm{~A}, \operatorname{blaZ}, \operatorname{erm} \mathrm{A}, \operatorname{erm} \mathrm{C}, m s r(\mathrm{~A} / \mathrm{B}), m p h \mathrm{C}$ & $h l \mathrm{~B}$ & $105(5)$ & $\mathrm{t} 10682$ & II & II \\
\hline VS2774 & FOX, PEN, ERY, DA ${ }^{1}, \mathrm{CIP}$ & $m e c \mathrm{~A}$, blaZ, erm $\mathrm{A}, m p h \mathrm{C}$ & $h l \mathrm{~B}$, et $A$ & $22(22)$ & t18526 & IV & $\mathrm{I}$ \\
\hline VS2775 & FOX, PEN, ERY, DA ${ }^{2}, \mathrm{CIP}$ & $m e c \mathrm{~A}, \operatorname{blaZ}, \operatorname{erm} \mathrm{A}, \operatorname{erm} \mathrm{C}, m s r(\mathrm{~A} / \mathrm{B})$ & $h l \mathrm{~B}$, et $A$ & $22(22)$ & $\mathrm{t} 1370$ & IV & I \\
\hline VS2776 & FOX, PEN, FD & mecA, blaZ & $h l \mathrm{~B}$ & $8(8)$ & t008 & IV & I \\
\hline
\end{tabular}

${ }^{1}$ Constitutive $\mathrm{MLS}_{\mathrm{B}}\left(\mathrm{cMLS}_{\mathrm{B}}\right)$ phenotype; ${ }^{2}$ Inducible $\mathrm{MLS}_{\mathrm{B}}\left(\mathrm{iMLS}_{\mathrm{B}}\right)$ phenotype; FOX: cefoxitin; PEN: penicillin; ERY: erythromycin; DA: clindamycin; CN: gentamicin; TOB: tobramycin; CIP: ciprofloxacin; FD: fusidic acid; MLST: multilocus sequence typing; ST: sequence type; CC: clonal complex; SCCmec: staphylococcal cassette chromosome mec; ${ }^{\text {a }}$ mecA gene encodes the protein PBP2A; blaZ encodes the protein BlaZ; erm genes encode the rRNA adenine N-6-methyltransferase, $m s r(\mathrm{~A} / \mathrm{B})$ encodes the peptide methionine sulfoxide reductase; $m p h \mathrm{C}$ encodes the macrolide 2'-phosphotransferase; aac (6')-Ie-aph(2")-Ia encodes the bifunctional enzyme AAC/APH; and ant (4')-Ia encodes the aminoglycoside O-nucleotidyltransferase ANT(4')-Ia 
The majority of the isolates $(n=9)$ were typed as ST22 and SCCmec IV, also known as the EMRSA-15 clone. Six of these isolates were spa-type t747, and the other three were t020, t18526, and t1370. EMRSA-15 isolates were resistant to penicillin, and eight out of nine harbored the blaZ gene. Seven isolates showed resistance to erythromycin, and three were coresistant to clindamycin, showing a constitutive $\mathrm{MLS}_{\mathrm{B}}\left(\mathrm{cMLS} \mathrm{S}_{\mathrm{B}}\right.$ ) phenotype. Four erythromycin-resistant isolates did not show clindamycin resistance; however, they were positive upon D-testing and were considered inducible $\mathrm{MLS}_{\mathrm{B}}\left(\mathrm{iMLS}_{\mathrm{B}}\right)$ isolates. The observed $\mathrm{MLS}_{\mathrm{B}}$ phenotypes were mostly determined by identification of combinations of two or more genes: $\operatorname{erm} \mathrm{C}+m s r(\mathrm{~A} / \mathrm{B})(n=1), \operatorname{erm} \mathrm{A}+m p h \mathrm{C}(n=1), \operatorname{erm} \mathrm{A}+\operatorname{erm} \mathrm{C}+m s r(\mathrm{~A} / \mathrm{B})(n=1)$, and $\operatorname{erm} \mathrm{C}+m s r(\mathrm{~A} / \mathrm{B})+m p h \mathrm{C}(n=4)$. Only one isolate was resistant to aminoglycosides, namely gentamicin and tobramycin, and harbored the resistance genes aac(6')-Ie-aph(2")-Ia and ant( $\left.4^{\prime}\right)$-Ia. Regarding the virulence factors, three isolates were PVL-positive, all isolates harbored the genes encoding hemolysins, and eight isolates carried the eta gene. All EMRSA-15 isolates belonged to agr type I.

Two isolates were typed as ST5-SCCmec II and one isolate as ST105-SCCmec II (New York/Japan and New York/Japan (related) clones, respectively). Both isolates were ascribed to spa-type t002. These isolates showed resistance to penicillin and ciprofloxacin and harbored the blaZ resistance gene. Two isolates showed an $\mathrm{iMLS}_{\mathrm{B}}$ phenotype and carried the gene combinations of $\operatorname{ermA}+m s r(\mathrm{~A} / \mathrm{B})$ and $m s r(\mathrm{~A} / \mathrm{B})+m p h \mathrm{C}$. One isolate carried the $a a c\left(6^{\prime}\right)$-Ie- $a p h\left(2^{\prime \prime}\right)$-Ia gene encoding resistance to gentamicin. None of the isolates were positive for PVL; nevertheless, all isolates were positive for genes encoding hemolysins, and all were agr type II.

Finally, two isolates belonged to ST8 and SCCmec type IV (variant of the USA300 clone). Both isolates were typed as $\mathrm{t} 008$. One of the isolates showed a multidrug-resistant phenotype with resistance to penicillin, ciprofloxacin, and erythromycin and inducible resistance to clindamycin, harboring the respective resistance genes blaZ, $\operatorname{erm} \mathrm{C}, m s r(\mathrm{~A} / \mathrm{B})$, and $m p h \mathrm{C}$. The second isolate showed resistance to penicillin and fusidic acid. Both isolates belonged to $a g r$ type I and carried the genes encoding alpha- and beta-hemolysins.

\section{Discussion}

A total of 103 cases of bacteremia were identified at the local hospital between 2016 and 2019, of which $15.5 \%$ were caused by MRSA. All isolates were typically epidemic hospital-acquired MRSA (HA-MRSA) clones. MRSA bacteremia has been reported worldwide, and its frequency varies from one country to another. In 2018, the percentage of invasive MRSA in bacteremia in different parts of Europe varied from $0.0 \%$ to $43.0 \%$ with an average of $16.4 \%$ [15]. Notably, in Southern European countries, such as Italy, Romania, Greece, and Cyprus, these rates were higher than in other European countries. In Portugal, the percentage of invasive MRSA in bacteremia was $38.1 \%$. MRSA bacteremia treatment is challenging, especially when dealing with multidrug-resistant strains. Indeed, in our study, 12 of the 16 isolates were considered multidrug-resistant since they presented resistance to antibiotics belonging to at least three distinct classes of antimicrobials.

EMRSA-15 is one of the most recurrent HA-MRSA clonal lineages in recent years [16,17]. This clone is known for its rapid spread and is responsible for causing several invasive infections, such as bacteremia [18]. EMRSA-15 carries SCCmec type IV, which is frequent in HA-MRSA clones and is smaller and has a lower fitness cost compared to SCCmec types II and III, increasing the clone's ability to spread worldwide [19]. In 2013, a study conducted by Faria et al. reported that EMRSA-15, followed by ST105-II, was the dominant clone among MRSA bloodstream infections in Portugal [20]. EMRSA-15 was also the predominant clone found in our study. Since 2001, this clone has been repeatedly isolated in hospitalized patients, communities, the environment, and animals in Portugal, replacing the resident HA-MRSA clones and becoming the main clone in this country [21]. Initially, the EMRSA-15 clone in Portugal was characterized by spa-types $\mathrm{t} 747, \mathrm{t} 032$, and $\mathrm{t} 2357$; however, as EMRSA-15 became the main clone, there was an increase in spa diversity [20]. Nevertheless, in this study, spa-type 7747 was the most common. One of the EMRSA-15 isolates belonged to spa-type t020, which is a well-established 
type in Germany and is highly associated with EMRSA-15 [22,23]. spa-types t18526 and t1370 were also detected in this study, each in one isolate. The spa-type t18526 was reported for the first time in one of our previous studies conducted with samples from the same hospital with MRSA strains isolated from infected diabetic foot ulcers, in which the most prevalent clone and spa-type were also EMRSA-15 and $t 747$ [9]. As for $\mathrm{t} 1370$, it was the predominant clone in an outbreak in a neonatal unit in the UK and in human patients in New Zealand and was always associated with EMRSA-15 [24,25]. The presence of PVL-encoding genes was only detected in EMRSA-15 isolates. Similar results were obtained by Goudarzi et al. when studying the molecular characteristics of MRSA strains from patients with bacteremia [26]. Although the PVL toxin is often associated with skin and soft-tissue infections, studies have shown an association between PVL and severe invasive infections [27]. PVL and SCCmec type IV presence are often used as markers of community-associated MRSA (CA-MRSA). This assumption may be inaccurate since it frequently includes the EMRSA-15 and USA800 clones, which are epidemiologically HA-MRSA [18]. The eta gene was found only among EMRSA-15 isolates, and consistent with other studies, all eta genes belonged to SCCmec type IV [26]. Furthermore, the etb gene was not detected in our study, which is in accordance with other studies that showed that invasive MRSA strains carried the eta gene but few or none carried the etb gene [26,28]. All EMRSA-15 isolates in our study belonged to $a g r$ type I, in agreement with other studies in which $a g r$ I, followed by $a g r$ II, was the most common type in MRSA bacteremia [29,30]. Furthermore, Ben Ayed et al. showed that $a g r$ I was associated with invasive infections, bacteremia in particular [31]. However, agr locus is strongly associated with bacterial genetic background, and therefore its prevalence may be driven by the genotypes circulating in each hospital. Goudarzi et al. reported that MRSA bacteremia isolates belonging to SCCmec IV and II isolates were distributed among agr type III [26]. In another study, $a g r$ II was the most common agr type in MRSA bacteremia strains, followed by agr I; however, the majority of strains belonged to CC5, which suggests that agr type may also be associated with clonal complex [32]. Indeed, Aschbacher et al. showed that bacteremia isolates belonging to CC22, CC5, and CC8 were agr types I, II, and I, respectively [30]. These results are in accordance with our study, in which all USA300 isolates belonged to $a g r$ type I, and all New York/Japan clones were $a g r$ type II. Three New York/Japan (or related) clones were detected in bacteremia isolates. This clone has been reported to be associated with bacteremia and is the most prevalent in France and South Korea [33,34]. The New York/Japan clone and ST105-MRSA-II were also found in bacteremia isolates in the study by Faria et al., who suggested that the ST105-MRSA-II clone could replace EMRSA-15 and be the next clonal wave of MRSA in Portuguese hospitals [20]. Nevertheless, this shift was not confirmed, since our studies and other recent studies in Portugal showed that there was no modification in the predominance of EMRSA-15 [9]. Furthermore, the New York/Japan clone seems to be significantly decreasing in prevalence in hospitals [35,36]. spa-type t002 is strongly linked with ST105-MRSA-II, since most New York/Japan isolates reported are type t002. Two ST8-MRSA-IV clones were also isolated in our study. These clones are a variant of the epidemic clone USA300, since this clone is linked to carriage of PVL and both of our isolates were PVL-negative. USA300 is sporadically isolated in MRSA infections in Portugal; this clone is frequently found in the United States (spa-type t008), where it is often responsible for bacteremia, and is found to a much lesser extent in Europe and the rest of the world [37].

Twelve of the sixteen isolates were resistant to erythromycin; however, only three showed coresistance to clindamycin and as such were categorized as $\mathrm{CMLS}_{\mathrm{B}}$. Those nine isolates were further characterized by D-test to the $\mathrm{MLS}_{\mathrm{B}}$ phenotype. All showed the inducible $\mathrm{MLS}_{\mathrm{B}}$ phenotype. Both $\mathrm{cMLS}_{\mathrm{B}}$ and $\mathrm{iMLS}_{\mathrm{B}}$ harbored several combinations of genes conferring resistance to macrolides and lincosamides; however, erm $\mathrm{A}$, erm $\mathrm{C}$, or both were present in all isolates. The erm $\mathrm{A}$ and erm $\mathrm{C}$ genes are the genes most commonly found in $\mathrm{MLS}_{\mathrm{B}}$-resistant $S$. aureus; nevertheless, $\mathrm{MLS}_{\mathrm{B}}$-resistant MRSA often carries combinations of two or more resistance genes $[7,38]$. In staphylococci showing an iMLS $S_{B}$ phenotype, the methylase mRNA produced by bacteria is inactive, and the activation only occurs in the presence of a macrolide. In contrast, in the $\mathrm{CMLS}_{\mathrm{B}}$-resistance phenotype, active methylase mRNA is produced in the absence of a macrolide [38]. Therefore, identifying the $\mathrm{MLS}_{\mathrm{B}}$-resistance phenotype 
is essential since strains presenting an $\mathrm{iMLS}_{\mathrm{B}}$ phenotype may switch to a $\mathrm{CMLS}_{\mathrm{B}}$ phenotype under antibiotic pressure, which may lead to treatment failure [38].

\section{Material and Methods}

\subsection{Bacterial Isolates}

Blood samples were collected from 103 inpatients with bacteremia infection hospitalized at the Hospital Centre of Trás-os-Montes e Alto Douro E.P.E., Vila Real, Portugal, from 2016 to 2019. A small volume of blood culture was inoculated on an oxacillin-resistance-screening agar base (ORSAB) (OXOID) supplemented with $2 \mathrm{mg} / \mathrm{L}$ of oxacillin to isolate MRSA strains and incubated at $37^{\circ} \mathrm{C}$ for $24 \mathrm{~h}$. Four colonies from each plate were recovered and seeded onto Baird-Parker agar plates for further identification of possible S. aureus. MRSA strains were identified based on Gram staining, biochemical tests (catalase, DNase, and coagulase), and genotyping.

\subsection{Antimicrobial Resistance Profile}

MRSA strains were characterized according to their antibiotic resistance profiles using the Kirby-Bauer disk-diffusion method against 14 antimicrobial agents: cefoxitin $(30 \mu \mathrm{g})$, chloramphenicol $(30 \mu \mathrm{g})$, ciprofloxacin $(5 \mu \mathrm{g})$, clindamycin $(2 \mu \mathrm{g})$, erythromycin $(15 \mu \mathrm{g})$, fusidic acid $(10 \mu \mathrm{g})$, gentamicin $(10 \mu \mathrm{g})$, kanamycin $(30 \mu \mathrm{g})$, linezolid $(10 \mu \mathrm{g})$, mupirocin $(200 \mu \mathrm{g})$, penicillin $(1 \mathrm{U})$, tetracycline $(30 \mu \mathrm{g})$, tobramycin $(10 \mu \mathrm{g})$, and trimethoprim/sulfamethoxazole $(1.25 / 23.75 \mu \mathrm{g})$. The tests were performed according to the European Committee on Antimicrobial Susceptibility Testing (EUCAST, 2018) guidelines except the test for kanamycin, which followed Clinical and Laboratory Standards Institute standards (CLSI, 2017). Isolates showing resistance to erythromycin were further characterized by double-disk diffusion (D-test) to determine the MLS $\mathrm{B}_{\mathrm{B}}$ phenotype. Briefly, erythromycin and clindamycin disks were placed onto inoculated Muller-Hinton plates $15 \mathrm{~mm}$ apart from edge to edge. If the inhibition zone around the clindamycin disk showed a D-shape, the isolate was considered to have an inducible $\mathrm{MLS}_{\mathrm{B}}\left(\mathrm{iMLS}_{\mathrm{B}}\right.$ ) phenotype. Resistance to both erythromycin and clindamycin indicated a constitutive $\mathrm{MLS}_{\mathrm{B}}\left(\mathrm{CMLS}_{\mathrm{B}}\right)$ phenotype [39]. Quality control was performed with S. aureus strain ATCC 25923.

DNA was extracted from fresh cultures as previously described [9]. Briefly, two colonies of fresh cultures from each isolate were suspended in $45 \mu \mathrm{L}$ of Milli-Q water. Five microliters of lysostaphin $(1 \mathrm{mg} / \mathrm{mL})$ was added, and the samples were incubated for $10 \mathrm{~min}$ at $37^{\circ} \mathrm{C}$. Then, $150 \mu \mathrm{L}$ of Tris-HCl $(0.1 \mathrm{M}), 45 \mu \mathrm{L}$ of Milli-Q water, and $5 \mu \mathrm{L}$ of proteinase $\mathrm{K}(2 \mathrm{mg} / \mathrm{mL})$ were added, and the samples were incubated at $67^{\circ} \mathrm{C}$ for $10 \mathrm{~min}$. Lastly, the samples were boiled for $5 \mathrm{~min}$ at $100^{\circ} \mathrm{C}$.

According to the phenotypic resistance of each isolate, the presence of the following antibiotic resistance genes was investigated by polymerase chain reaction (PCR): blaZ, erm(A), $\operatorname{erm}(\mathrm{B}), \operatorname{erm}(\mathrm{C})$, $\operatorname{erm}(\mathrm{T}), \operatorname{erm}(\mathrm{Y}), m s r(\mathrm{~A} / \mathrm{B}), m p h \mathrm{C}, \operatorname{lin} \mathrm{B}, v g a \mathrm{~B}, v g a \mathrm{C}, \operatorname{aac}\left(6^{\prime}\right)-\mathrm{Ie}-\operatorname{aph}\left(2^{\prime \prime}\right)-\mathrm{Ia}, \operatorname{ant}\left(4^{\prime}\right)-\mathrm{Ia}, f u s \mathrm{~B}$, and $f u s \mathrm{C}$ (Supplementary Table S1).

\subsection{Characterization of Virulence Factors}

The presence of the virulence genes encoding alpha- and beta-hemolysins (hla and hlb), exfoliative toxins (eta and etb), toxic shock syndrome toxin (tst), and Panton-Valentine leucocidin (PVL) (lukF/lukS-PV) was determined by PCR (Supplementary Table S1). Positive and negative controls used in all experiments belonged to the strain collection of University of Trás-os-Montes and Alto Douro.

\subsection{Molecular Characterization}

Multilocus sequence typing (MLST) and spa typing were performed for all isolates as previously described, supported by the public databases MLST and the Ridom SpaServer. According to the sequence type (ST), each isolate was grouped according to the corresponding clonal complex (CC). 
All isolates were characterized by agr typing and staphylococcal chromosomal cassette mec (SCCmec) typing (I-V) using specific primers (Supplementary Table S1).

\section{Conclusions}

We found epidemic HA-MRSA clones, namely EMRSA-15, USA300, and New York/Japan, in samples recovered from bloodstream infections over a period of 3 years. Our results corroborate the relatively high prevalence of EMRSA-15 circulating in Portuguese hospitals. Most isolates were multidrug-resistant and presented an iMLSB or cMLSB phenotype, which may result in a therapeutic problem of inadequacy of antibiotic treatment and lead to high morbidity and mortality.

Supplementary Materials: The following are available online at http://www.mdpi.com/2079-6382/9/7/375/s1: Table S1: Primers used for molecular typing and detection of antimicrobial resistance genes in MRSA strains.

Author Contributions: Conceptualization, V.S. and P.P.; methodology, V.S., S.H., and C.F.; validation, C.M.M., R.C., C.A.-C., G.I., and P.P.; investigation, V.S., S.H., C.F., R.C., and C.A.-C.; resources, I.C.; writing—original draft preparation, V.S.; supervision, C.M.M., J.E.P., L.M., J.L.C., G.I., and P.P.; funding acquisition, R.C. and C.A.-C. All authors have read and agreed to the published version of the manuscript.

Funding: This research was funded by the Ministerio de Ciencia, Innovación y Universidades (Spain, Project RTI2018-098267-R-C33) and the Junta de Castilla y León (Consejería de Educación, Spain, Project LE164G18).

Acknowledgments: This work was funded by the R\&D Project CAREBIO2-comparative assessment of antimicrobial resistance in environmental biofilms through proteomics-toward innovative theranostic biomarkers, with references NORTE-01-0145-FEDER-030101 and PTDC/SAU-INF/30101/2017, financed by the European Regional Development Fund (ERDF) through the Northern Regional Operational Program (NORTE 2020) and the Foundation for Science and Technology (FCT). This work was supported by the Associate Laboratory for Green Chemistry (LAQV), which is financed by national funds from FCT/MCTES (UIDB/50006/2020). Vanessa Silva and Isabel Carvalho are grateful to FCT (Fundação para a Ciência e a Tecnologia) for financial support through Ph.D. grants SFRH/BD/137947/2018 and SFRH/BD/133266/2017.

Conflicts of Interest: The authors declare no conflict of interest.

\section{References}

1. Mohanty, A.; Mohapatra, K.; Pal, B. Isolation and identification of staphylococcus aureus from skin and soft tissue infection in sepsis cases, Odisha. J. Pure Appl. Microbiol. 2018, 12, 419-424. [CrossRef]

2. Powers, M.E.; Wardenburg, J.B. Igniting the fire: Staphylococcus aureus virulence factors in the pathogenesis of sepsis. PLoS Pathog. 2014, 10, e1003871. [CrossRef] [PubMed]

3. Zha, G.-F.; Wang, S.-M.; Rakesh, K.P.; Bukhari, S.N.A.; Manukumar, H.M.; Vivek, H.K.; Mallesha, N.; Qin, H.-L. Discovery of novel arylethenesulfonyl fluorides as potential candidates against methicillin-resistant of Staphylococcus aureus (MRSA) for overcoming multidrug resistance of bacterial infections. Eur. J. Med. Chem. 2019, 162, 364-377. [CrossRef] [PubMed]

4. Kong, E.F.; Johnson, J.K.; Jabra-Rizk, M.A. Community-associated methicillin-resistant Staphylococcus aureus: An enemy amidst us. PLoS Pathog. 2016, 12, e1005837. [CrossRef]

5. Prabhu, K.; Rao, S.; Rao, V. Inducible clindamycin resistance in Staphylococcus aureus isolated from clinical samples. J. Lab. Physicians 2011, 3, 25-27. [CrossRef]

6. Coutinho, V.D.L.S.; Paiva, R.M.; Reiter, K.C.; de-Paris, F.; Barth, A.L.; Machado, A.B.M.P. Distribution of erm genes and low prevalence of inducible resistance to clindamycin among staphylococci isolates. Braz. J. Infect. Dis. 2010, 14, 564-568.

7. Khodabandeh, M.; Mohammadi, M.; Abdolsalehi, M.R.; Alvandimanesh, A.; Gholami, M.; Bibalan, M.H.; Pournajaf, A.; Kafshgari, R.; Rajabnia, R. Analysis of resistance to macrolide-lincosamide-streptogramin B among mecA-positive Staphylococcus aureus isolates. Osong Public Health Res. Perspect. 2019, 10, $25-31$. [CrossRef]

8. Lakhundi, S.; Zhang, K. Methicillin-resistant Staphylococcus aureus: Molecular characterization, evolution, and epidemiology. Clin. Microbiol. Rev. 2018, 31, e00020-18. [CrossRef] 
9. Silva, V.; Almeida, F.; Carvalho, J.A.; Castro, A.P.; Ferreira, E.; Manageiro, V.; Tejedor-Junco, M.T.; Caniça, M.; Igrejas, G.; Poeta, P. Emergence of community-acquired methicillin-resistant Staphylococcus aureus EMRSA-15 clone as the predominant cause of diabetic foot ulcer infections in Portugal. Eur. J. Clin. Microbiol. Infect. Dis. 2020, 39, 179-186. [CrossRef]

10. Dat, V.Q.; Vu, H.N.; Nguyen The, H.; Nguyen, H.T.; Hoang, L.B.; Vu Tien Viet, D.; Bui, C.L.; Van Nguyen, K.; Nguyen, T.V.; Trinh, D.T.; et al. Bacterial bloodstream infections in a tertiary infectious diseases hospital in Northern Vietnam: Aetiology, drug resistance, and treatment outcome. BMC Infect. Dis. 2017, 17, 493. [CrossRef]

11. Tong, S.Y.C.; Davis, J.S.; Eichenberger, E.; Holland, T.L.; Fowler, V.G., Jr. Staphylococcus aureus infections: Epidemiology, pathophysiology, clinical manifestations, and management. Clin. Microbiol. Rev. 2015, 28, 603-661. [CrossRef] [PubMed]

12. Hassoun, A.; Linden, P.K.; Friedman, B. Incidence, prevalence, and management of MRSA bacteremia across patient populations-A review of recent developments in MRSA management and treatment. Crit. Care 2017, 21, 211. [CrossRef] [PubMed]

13. Piechota, M.; Kot, B.; Frankowska-Maciejewska, A.; Gruzewska, A.; Woźniak-Kosek, A. Biofilm formation by Methicillin-resistant and Methicillin-sensitive Staphylococcus aureus strains from hospitalized patients in Poland. Biomed. Res. Int. 2018, 2018, 7. [CrossRef] [PubMed]

14. Jokinen, E.; Lindholm, L.; Huttunen, R.; Huhtala, H.; Vuento, R.; Vuopio, J.; Syrjänen, J. Spa type distribution in MRSA and MSSA bacteremias and association of spa clonal complexes with the clinical characteristics of bacteremia. Eur. J. Clin. Microbiol. Infect. Dis. 2018, 37, 937-943. [CrossRef]

15. Antimicrobial Consumption in the EU/EEA, Annual Epidemiological Report for 2018. Available online: https: //www.ecdc.europa.eu/sites/default/files/documents/Antimicrobial-consumption-EU-EEA.pdf (accessed on 10 April 2020).

16. Lindsay, J.A. Hospital-associated MRSA and antibiotic resistance-What have we learned from genomics? Int. J. Med. Microbiol. 2013, 303, 318-323. [CrossRef]

17. Horváth, A.; Dobay, O.; Sahin-Tóth, J.; Juhász, E.; Pongrácz, J.; Iván, M.; Fazakas, E.; Kristóf, K. Characterisation of antibiotic resistance, virulence, clonality and mortality in MRSA and MSSA bloodstream infections at a tertiary-level hospital in Hungary: A 6-year retrospective study. Ann. Clin. Microbiol. Antimicrob. 2020, 19, 1-11. [CrossRef]

18. Bal, A.M.; Coombs, G.W.; Holden, M.T.G.; Lindsay, J.A.; Nimmo, G.R.; Tattevin, P.; Skov, R.L. Genomic insights into the emergence and spread of international clones of healthcare-, community-and livestock-associated meticillin-resistant Staphylococcus aureus: Blurring of the traditional definitions. J. Glob. Antimicrob. Resist. 2016, 6, 95-101. [CrossRef]

19. Knight, G.M.; Budd, E.L.; Lindsay, J.A. Large mobile genetic elements carrying resistance genes that do not confer a fitness burden in healthcare-associated meticillin-resistant Staphylococcus aureus. Microbiology (UK) 2013, 159, 1661-1672. [CrossRef]

20. Faria, N.A.; Miragaia, M.; de Lencastre, H.; The Multi Laboratory Project Collaborators. Massive dissemination of methicillin resistant Staphylococcus aureus in bloodstream infections in a high MRSA prevalence country: Establishment and diversification of EMRSA-15. Microb. Drug Resist. 2013, 19, 483-490. [CrossRef]

21. Aires-de-Sousa, M.; Correia, B.; de Lencastre, H.; Collaborators, M.P. Changing patterns in frequency of recovery of five methicillin-resistant Staphylococcus aureus clones in Portuguese hospitals: Surveillance over a 16-year period. J. Clin. Microbiol. 2008, 46, 2912-2917. [CrossRef]

22. Reinheimer, C.; Kempf, V.A.J.; Jozsa, K.; Wichelhaus, T.A.; Hogardt, M.; O’Rourke, F.; Brandt, C. Prevalence of multidrug-resistant organisms in refugee patients, medical tourists and domestic patients admitted to a German university hospital. BMC Infect. Dis. 2017, 17, 17. [CrossRef]

23. Chan, M.K.L.; Koo, S.H.; Quek, Q.; Pang, W.S.; Jiang, B.; Ng, L.S.Y.; Tan, S.H.; Tan, T.Y. Development of a real-time assay to determine the frequency of qac genes in methicillin resistant Staphylococcus aureus. J. Microbiol. Methods 2018, 153, 133-138. [CrossRef]

24. Williamson, D.A.; Roberts, S.A.; Ritchie, S.R.; Coombs, G.W.; Fraser, J.D.; Heffernan, H. Clinical and molecular epidemiology of methicillin-resistant Staphylococcus aureus in New Zealand: Rapid emergence of sequence type 5 (ST5)-SCCmec-IV as the dominant community-associated MRSA clone. PLoS ONE 2013, 8, e62020. [CrossRef] 
25. Otter, J.A.; Klein, J.L.; Watts, T.L.; Kearns, A.M.; French, G.L. Identification and control of an outbreak of ciprofloxacin-susceptible EMRSA-15 on a neonatal unit. J. Hosp. Infect. 2007, 67, 232-239. [CrossRef]

26. Goudarzi, M.; Seyedjavadi, S.S.; Nasiri, M.J.; Goudarzi, H.; Sajadi Nia, R.; Dabiri, H. Molecular characteristics of methicillin-resistant Staphylococcus aureus (MRSA) strains isolated from patients with bacteremia based on MLST, SCCmec, spa, and agr locus types analysis. Microb. Pathog. 2017, 104, 328-335. [CrossRef]

27. Shallcross, L.J.; Fragaszy, E.; Johnson, A.M.; Hayward, A.C. The role of the Panton-Valentine leucocidin toxin in staphylococcal disease: A systematic review and meta-analysis. Lancet. Infect. Dis. 2013, 13, 43-54. [CrossRef]

28. Sila, J.; Sauer, P.; Kolar, M. Comparison of the prevalence of genes coding for enterotoxins, exfoliatins, Panton-Valentine leukocidin and TSST-1 between methicillin-resistant and methicillin-susceptible isolates of Staphylococcus Aureus at the University Hospital in Olomouc. Biomed. Pap. 2009, 153, 215-218. [CrossRef]

29. Abdulgader, S.M.; van Rijswijk, A.; Whitelaw, A.; Newton-Foot, M. The association between pathogen factors and clinical outcomes in patients with Staphylococcus aureus bacteraemia in a tertiary hospital, Cape Town. Int. J. Infect. Dis. 2020, 91, 111-118. [CrossRef]

30. Aschbacher, R.; Pagani, E.; Larcher, C.; Pichon, B.; Pike, R.; Ganner, M.; Hill, R.; Kearns, A.; Wootton, M.; Davies, L.; et al. Molecular epidemiology of methicillin-resistant Staphylococcus aureus from bacteraemia in northern Italy. Infez. Med. 2012, 20, 256-264.

31. Ben Ayed, S.; Boutiba-Ben Boubaker, I.; Samir, E.; Ben Redjeb, S. Prevalence of agr specificity groups among methicilin resistant Staphylococcus aureus circulating at Charles Nicolle hospital of Tunis. Pathol. Biol. 2006, 54, 435-438. [CrossRef]

32. He, W.; Chen, H.; Zhao, C.; Zhang, F.; Li, H.; Wang, Q.; Wang, X.; Wang, H. Population structure and characterisation of Staphylococcus aureus from bacteraemia at multiple hospitals in China: Association between antimicrobial resistance, toxin genes and genotypes. Int. J. Antimicrob. Agents 2013, 42, 211-219. [CrossRef]

33. Bouchiat, C.; Moreau, K.; Devillard, S.; Rasigade, J.-P.; Mosnier, A.; Geissmann, T.; Bes, M.; Tristan, A.; Lina, G.; Laurent, F.; et al. Staphylococcus aureus infective endocarditis versus bacteremia strains: Subtle genetic differences at stake. Infect. Genet. Evol. 2015, 36, 524-530. [CrossRef]

34. Kim, D.; Hong, J.S.; Yoon, E.-J.; Lee, H.; Kim, Y.A.; Shin, K.S.; Shin, J.H.; Uh, Y.; Shin, J.H.; Park, Y.S.; et al. Toxic shock syndrome toxin 1-producing methicillin-resistant Staphylococcus aureus of clonal complex 5 , the New York/Japan epidemic clone, causing a high early-mortality rate in patients with bloodstream infections. Antimicrob. Agents Chemother. 2019, 63, e01362-e01419. [CrossRef]

35. Boswihi, S.S.; Udo, E.E.; Al-Sweih, N. Shifts in the Clonal Distribution of Methicillin-Resistant Staphylococcus aureus in Kuwait Hospitals: 1992-2010. PLoS ONE 2016, 11, e0162744. [CrossRef]

36. Lee, C.-Y.; Fang, Y.-P.; Chang, Y.-F.; Wu, T.-H.; Yang, Y.-Y.; Huang, Y.-C. Comparison of molecular epidemiology of bloodstream methicillin-resistant Staphylococcus aureus isolates between a new and an old hospital in central Taiwan. Int. J. Infect. Dis. 2019, 79, 162-168. [CrossRef]

37. David, M.Z. The Importance of Staphylococcus aureus genotypes in outcomes and complications of bacteremia. Clin. Infect. Dis. 2019, 69, 1878-1880. [CrossRef]

38. Mišić, M.; Čukić, J.; Vidanović, D.; Šekler, M.; Matić, S.; Vukašinović, M.; Baskić, D. Prevalence of genotypes that determine resistance of staphylococci to macrolides and lincosamides in Serbia. Front. Public Health 2017, 5, 200. [CrossRef]

39. Sasirekha, B.; Usha, M.S.; Amruta, J.A.; Ankit, S.; Brinda, N.; Divya, R. Incidence of constitutive and inducible clindamycin resistance among hospital-associated Staphylococcus aureus. 3 Biotech. 2014, 4, 85-89. [CrossRef]

(C) 2020 by the authors. Licensee MDPI, Basel, Switzerland. This article is an open access article distributed under the terms and conditions of the Creative Commons Attribution (CC BY) license (http://creativecommons.org/licenses/by/4.0/). 